\title{
On relativist approaches to many-one identity
}

\author{
Martin A. Lipman ${ }^{1}$
}

Received: 11 May 2018 / Accepted: 16 August 2018 / Published online: 12 September 2018

(C) The Author(s) 2018

\begin{abstract}
Composition as identity is the view that a whole is identical to its parts taken collectively. Such a view raises the question of how the same portion of reality can be both one thing and many things. A primitivist view holds that there is no explanation to be had and that we simply need to accept that being one thing and being many things are compatible. One might think that we can do better by resorting to relativization. A relativist view may seem to explain how the same portion of reality can be both one thing and many things on the basis of the assumption that the portion of reality is these ways relative to different 'concepts' or 'counts'. This paper discusses whether relativization truly leads to a satisfactory explanation of how something can be both one thing and many things. The conclusion will be that, when we consider the current accounts of the involved parameters, these relativizations make no explanatory progress.
\end{abstract}

Keywords Composition as identity · Counts · Conceptualization · Ontological pluralism $\cdot$ Relativization $\cdot$ Primitivism about cardinality ascriptions

\section{Making sense of many-one identity}

Is a whole more than the sum of its parts? One might think that it isn't, that the parts are the same bit of world as the whole that they compose. Consider for example a deck of cards. Wherever the deck goes, the cards go as well (Sider 2007: p. 75). When a cashier sells the deck to me, I cannot be asked to pay for the 52 cards and be asked to pay for the deck (Baxter 1988: p. 85). The deck isn't a 53rd thing. The deck is nothing other than the 52 cards, it is just them. The same portion of reality is one deck and 52 cards, it's one thing and many things. This line of thought seems worthy of philosophical discussion.

凶 Martin A. Lipman

m.a.lipman@gmail.com

http://www.martinlipman.org

1 Institute for Philosophy, Leiden University, Nonnensteeg 1-3, 2311 BE Leiden, The Netherlands 
Let us assume that a whole isn't more than the sum of its parts, but identical to the parts taken collectively. How should we refer to that which is both one thing and many things? Lewis speaks of a 'portion of reality' (Lewis 1991: p. 81), which can then be described as one and many. But, of course, 'a portion' is a singular term referring to a single thing. When we say that a portion of reality is many things, should we say that it is three things, or should we say that it 'are three things'? Either option may sound awkward (though the second sounds worse than the first), but there is no way around this. We have to pick out something as one thing and say of $i t$ that it is many things or we may pick out many things and say of them that they are a single thing.

At the formal side of things, we need a notion of generalized identity (Cotnoir 2013) that can hold one-one, one-many, many-one and many-many. From here on, the relation '=' will refer to the generalized notion of identity, instead of the one-one relation we normally have in mind. We will assume that this generalized identity notion is intelligible (contra van Inwagen 1994), and that we can make sense of sentences such as 'the deck $=52$ cards' or 'the deck is identical to 52 cards'. Using the generalized notion of identity and a composition (or fusion) relation between parts and wholes, the thesis is simple: composition is equivalent to generalized identity, i.e. $\forall x \forall y y$ ( $x$ is composed of the $y y \leftrightarrow x=y y$ ).

Many-one identity seems prima facie problematic however. How can the same portion of reality be both many things and one thing? Being one in number and being many in number are incompatible ways for something to be (Lewis 1991: p. 87). To be many is to be more than one and to be one is to be fewer than many. How can the same thing be both? This is a key challenge to any composition as identity view. The challenge is underwritten by what Carrara and Lando (2017) call the numerical discernibility argument (where $u u$ is a constant picking out a plurality) ${ }^{1}$ :

(1) $t$ is the sum of $u u$

(2) $t$ is one thing

(3) if $t$ is one thing, then $t$ is not many things

(4) $t$ is not many things

$(2,3, \mathrm{MP})$

(5) $u u$ are many things

(C) $t$ is not identical to $u u$

Resistance to the argument must either find fault with one of the assumptions or with Leibniz's Law (LL). ${ }^{2}$ Tinkering with Leibniz's Law raises the worry that the notion of identity involved in the composition as identity thesis is merely some identity-like relation or that composition and identity are merely in the same family of sameness relations rather than being the very same relation (Lewis 1991: p. 85). It's not clear whether such weaker views do justice to the driving intuition that the whole and the parts are just one and the same thing (Sider 2007: p. 59) and whether this weaker

\footnotetext{
1 Carrara and Lando (2017: p. 493) construe the argument as involving only two premises (using a conjunction of the assumptions (2), (4) and (5) listed here, i.e. ' $u u$ are three and not one; $t$ is one and not three'). See Spencer (2017: p. 860) for another formulation.

2 I will take Leibniz's Law to be the following biconditional: $\forall x \forall y(x=y \leftrightarrow(\varphi(x) \leftrightarrow \varphi(y))$. Here $\varphi$ is schematic for open sentences and ranges only over extensional open sentences.
} 
thesis can do any interesting philosophical work, such as rendering an ontological commitment to wholes 'innocent' (Lewis 1991: p. 81).

What we are after is a way of making sense of composition as identity and this arguably requires an identity relation that satisfies Leibniz's Law. From here on, when I refer to the composition as identity thesis, I refer to views that leave the indiscernibility of identicals intact. Such views have to find fault with one of the other assumptions involved in the numerical discernibility argument. ${ }^{3}$

Another option is to reject that being one thing and being many things are incompatible ways for something to be, that is, to reject premise (3) in the discernibility argument. If being one thing is not incompatible with being many things, then if something is one thing this doesn't imply that it's not many things, thus allowing that some single thing is many things as well (critically discussed in Cameron 2012; McDaniel 2008; Sider 2007, 2014; Yi 1999). Contrary to common presumption, being one thing and being many things are compatible ways of being and hence one and the same thing can be both one thing and many things.

The challenge for this approach is to explain what it is to be one thing and what it is to be many things. On the standard understanding of these cardinalities they are contraries. The standard account of cardinality ascriptions are as follows ${ }^{4}$ :

$t$ is exactly one thing $={ }_{\mathrm{df}} \exists x(x \prec t \wedge \forall y(w \prec t \rightarrow y=x))$

$u u$ are exactly three things $={ }_{\mathrm{df}} \exists x \exists y \exists z(x \neq y \wedge y \neq z \wedge x \neq z \wedge x \prec u u \wedge y \prec u u$

$\wedge z \prec u u \wedge \forall w(w \prec u u \rightarrow w=x \vee w=y \vee w=z)$

Thus defined, the cardinality ascriptions $d o$ generate contradictions (given the assumption that $t=u u$ and given that we assume Leibniz's Law; see Spencer 2017: p. 862). If some object $x$ is both exactly one thing and exactly three things in the senses defined above, there are and aren't three distinct things that belong to $x$. The view under discussion-which assumes that something can be both one thing and many things-must therefore deny the standard definitions of cardinality ascriptions. ${ }^{5}$

One response here is to take the cardinality ascriptions to be primitive predicates. Call this the primitivist view. Although these cardinality primitives do not have an analysis according to the primitivist view, one may elucidate the cardinality ascriptions by specifying some of the inferential relations that hold for these primitives. Some inferential relations seem to be non-negotiable if the alleged cardinality ascriptions are truly cardinality ascriptions. As we trace such inferential relations, primitivism is bound to spread somewhat through our ideological framework. For example, we

\footnotetext{
${ }^{3}$ Let me mention two radical options, just to set them aside. One could argue that there is no real plurality, thus rejecting assumption (5), or that there is no unity, thus rejecting assumption (2) of the argument. These options solve the problem by privileging one of the two cardinality attributions and rejecting the other. Such views may be interesting in their own right but are not plausible ways of defending the composition as identity thesis. Just as the denial of Leibniz's Law raises the suspicion that identity is no longer really involved in the view, the denial of one of the two cardinality attributions raises the worry that there is no longer any genuine composition involved. What we are after is a way of making sense of composition as identity, and this requires a relation between matters of different cardinalities.

${ }^{4}$ Here we use ' $\prec$ ' for the relation of is one of. We assume that a plurality can also consist of a single thing. Also, $t$ and $u u$ are here names for pluralities.

5 Spencer (2017) discusses independent reasons for rejecting the standard accounts of cardinality, building on an argument by Salmon (1997).
} 
can hardly deny that being exactly one thing implies being fewer than any two things. Given that being exactly three things implies being more than any two things, one must furthermore assume that the relational properties of being more than any two things and being fewer than any two things are compatible. Just as something can be both one thing and three things, something can be both fewer than two things and more than two things. On the primitivist view we need to reject not only premise (3) - that if something is one thing, then it's not many things - but also accounts of what it is to be one thing and of what it is to be many things, and of what it is to be more than a certain number and fewer than that number.

The primitivist view contrasts with a family of approaches to composition as identity that relativize attributions of cardinalities to certain parameters (Baxter 1988; Bohn 2014; Wallace 2011; Spencer 2017: §4). On these views, just as one might say that for some person to be loved is for there to be someone that loves that person, we should say that for something to be one thing is for there to be a certain parameter relative to which it's one thing and that, similarly, for something to be many things is for there to be a certain parameter relative to which it's many things. Something cannot be one thing and many things relative to the same parameter, but it can be one thing relative to one parameter and many things relative to a distinct parameter. Call this the relativist view.

Is the relativist view any better than the primitivist view? One might think so, since it might seem to explain how some portion of reality can be both one thing and many things, whereas the primitivist view simply submits that it can. But this alleged explanatory advantage is not so easy to evaluate. A relativist view raises some explanatory challenges of its own. In particular, what are these parameters relative to which the cardinality ascriptions are relativized and what is the nature of the relativization? These questions are central to a relativist view. For any philosophical puzzle, we could in principle posit some parameters and relativize the different premises of the puzzle to different parameters. Relativization to some postulated parameter is a schematic solution to any philosophical puzzle. Whether such a response is satisfactory depends on the nature of the invoked parameters and relativizations.

Concerning the nature of the parameters, two proposals have been made. One proposal is that we relativize cardinalities to ways of conceptualizing (Bohn 2014; cf. Wallace 2011). Another proposal is that we relativize cardinalities to so-called counts (Baxter 1988, 2014; Spencer 2017). It turns out that, when we think through these accounts of the parameters, no real explanatory progress is made beyond the primitivist view. ${ }^{6}$

\footnotetext{
6 One might think that, as a metaphysical thesis, the thesis must be stated in a fundamental language or as a thesis about fundamental reality (see e.g. Lewis 1983; Fine 2001; Dorr 2005; Sider 2011). Given that the many are identical to the single object that they compose, they cannot be more fundamental than it (assuming that something cannot be more fundamental than itself). It seems that the relevant thesis would be that it's in fundamental reality the case that wholes are identical to their parts. This might be problematic, however, as this forces all kinds of macroscopic ordinary objects to be part of fundamental reality. In any case, on this approach, the relativist would be purporting to explain how in fundamental reality, something can be both one thing and many things. The concerns of this paper apply just as well to the relativist explanation of this claim about cardinalities in fundamental reality. As it makes no substantive difference, I will not address the fundamentality formulation separately.
} 


\section{Relativization to ways of conceptualizing}

Let us first consider the view that relativizes the cardinality of a given portion of reality to ways of conceptualizing the given portion of reality. ${ }^{7}$ This view is defended by Bohn:

No ordinary thing has a particular cardinality independent of how it is conceptualized. Frege (1884) stressed this in various ways, perhaps most famously by the case of a deck of cards. I can hold one and the same thing in my hand and truly say of it that it is one deck of cards, but fifty-two cards. One and the same thing is thus 1 when thought of under (or picked out by) the concept of DECK OF CARDS, but 52 when thought of under (or picked out by) the concept CARD. (Bohn 2014: p. 145). ${ }^{8}$

The challenge of making sense of many-one identity is answered by relativizing cardinalities to conceptualizations of the relevant portion of reality under some concept, such as deck or card (I will be using italicization instead of capital letters to refer to concepts). ${ }^{9}$ Some portion of reality can be one relative to one such conceptualization and many relative to another. The motivating thought is that you cannot count something without conceiving of the target portion of reality under a certain concept and that this conceptualization determines how many things the portion of reality is. Call this concept-based relativism.

Consider the question this raises: how can the same portion of reality be adequately conceptualized as both a single deck and also as many cards? Note that we're asking about the compatibility of these conceptualizations. Certain conceptualizations are compatible and some conceptualizations are incompatible. Consider an easy case for illustration: whatever can be adequately conceptualized under the concept deck of cards cannot also be adequately conceptualized under the concept frog. Why not? To be adequately conceptualized as a deck requires that the portion of reality meets certain conditions, such as that it is composed of 52 cards of the right kind and suitable to play card games with. To be adequately conceptualized as a frog requires that the portion of reality meets certain other conditions, such as that it's an animate amphibian creature with certain properties. The conditions for being adequately conceptualized as a deck of card are incompatible with the conditions for being adequately conceptualized as a frog (since presumably nothing can be both an amphibian creature and be composed of 52 cards). When a portion of reality meets the requirements for being a deck of cards it thereby does not meet the requirements for being a frog. Conceptualizations as a deck of cards and as a frog are therefore incompatible.

\footnotetext{
7 The concept-based view has been criticized by Koslicki (1997) and Yi (2014) on the grounds that our ordinary concepts are not suitable for the view to work in full generality.

8 Frege discusses this in The Foundations of Arithmetic (1884: §46).

9 Although we focus on cardinalities, the issues apply to a broader family of properties, such as being amongst certain things, or being a member of the set formed by some things. For example, a card is amongst the 52 cards but is not amongst the deck of cards. On relativist views these expressions must be relativized in the same way as the cardinality ascriptions. For discussion of the issues, see Yi (1999: p. 146) and Sider (2007, 2014); for the relativist response to them, see Bohn (2014: pp. 146-147).
} 
Consider now the conceptualizations under the concept deck of cards and the conceptualization under the concept card. To conceptualize something as a card, it has to be roughly a single, typically flat carton-made object marked as playing a certain role in card games. Obviously, whatever can be adequately conceptualized as a deck of cards cannot adequately be conceptualized as a single card: the former requires that something is a single thing composed out of 52 cards and this is incompatible with being a single card. This everyone can agree on. Now for the more relevant question: can a portion that is adequately conceptualized under the concept of deck of cards be adequately conceptualized under the concept of 52 cards? Well, one might think, how could that be? A portion of reality has to be a single thing in order to be adequately conceptualized as a deck of cards and a portion of reality has to be many things in order to be adequately conceptualized as 52 cards. In whatever sense the adequate conceptualization of a portion of reality as a deck of cards excludes its being adequately conceptualized as a frog, why does its conceptualization as a deck not also exclude its being adequately conceptualizable as many things, for example as 52 cards? Note that the original question of how something can be both one thing and many things isn't substantially different from the question of how something can be adequately conceptualized as both one thing and many things. The concept-based relativist seems to push a bump around under the carpet.

One might object that there is something odd about building the cardinality ascriptions into the conceptualizations themselves: to resort to the conceptualization of a portion as a single card and the conceptualization of it as 52 cards. Indeed, note that Bohn, in the cited passage, only refers to the concepts card and deck. But building the cardinalities into the conceptualization is not central to the criticism. Here is a different way of framing the argument. Let us say that a conceptualization of some portion of reality under some concept $\mathrm{C}$ is 'adequate' when the cardinality of that portion of reality conceptualized under $\mathrm{C}$ is greater than $0 .{ }^{10} \mathrm{On}$ this picture, we apply a certain concept to a portion of reality and this 'outputs' a cardinality. The cardinality is in no way already part of the concept that we apply to the portion of reality. We will now say that the conceptualization of the relevant portion of reality under the concept deck of cards is 'adequate' in the sense that the cardinality of that portion of reality is 1. As before, we expect there to be conditions that a portion of reality has to meet for the application of a concept to deliver a certain cardinality. For the application of deck of cards to deliver cardinality 1, the relevant portion of reality must be composed of 52 cards of the right kind and be suitable to play card games with. The earlier talk of incompatibility can now be understood as follows: when the application of the concept deck of cards delivers a cardinality greater than 0 , then the application of the concept frog must deliver a cardinality of 0 . This is just to say that whenever the application of the concept of deck of cards is adequate, the application of the concept frog must be inadequate. Why? Well because of the different requirements that these concepts set on the world for delivering a cardinality greater than 0 .

On this way of thinking of conceptualizations, any portion of reality can be conceptualized under any concept, ones that include cardinality ascriptions and ones that do not. Take the portion of reality whose conceptualization under deck of cards delivers

$\overline{10}$ Thanks to an anonymous referee for suggesting this picture of conceptualizations. 
a cardinality of 1 . Its conceptualization under the concept single deck of cards also delivers a cardinality of 1 . Its conceptualization under single card would deliver a cardinality of 52, given that there are 52 single cards. Its conceptualization under 52 cards would presumably deliver a cardinality of 1 , given that we would have a single plurality of 52 cards. Although one need not conceptualize matters using concepts that incorporate cardinality ascriptions, it's not prohibited.

It should be clear what the relativist assumes: conceptualization under different concepts can deliver different cardinalities for the same portion of reality. Let us ask again: does this approach make any explanatory progress on how this can be? I do not think so. The relevant question remains: how can a portion that is adequately conceptualized under the concept deck of cards be adequately conceptualized under the concept of card? Assume that the conceptualization of the relevant portion of reality under deck of cards delivers a cardinality of 1. Everyone agrees that the conceptualization of this very same portion of reality under the concept card cannot also deliver a cardinality of 1 , since a single deck of cards cannot also be a single card. For the same reason, one might think that the conceptualization of this very same portion of reality under the concept card cannot deliver a cardinality of 52 either, since a requirement for delivering a cardinality of 52 under any conceptualization is that the relevant portion of reality is 52 things, but we already assumed that the conceptualization of the portion of reality under deck of cards delivers the cardinality 1, which requires the portion of reality to be a single thing. The question remains: why is it not the case that when the application of the concept deck of cards delivers a cardinality greater than 0 , the application of the concept card must deliver a cardinality of 0 (just as the application to it of the concept frog delivers a cardinality of 0 )? Anyone who is puzzled about how a certain portion of reality can be both one thing and many things will similarly be puzzled about how the application of two concepts can deliver the result that the relevant portion of reality has both a cardinality of 1 and of more than 1 . Relativization to conceptualizations doesn't do anything to clear the puzzlement.

It's important to be clear about the dialectic. The point isn't intended to be a direct counter-argument with the conclusion that composition as identity is false. To do so would clearly be question-begging, since it would be assuming that a single thing cannot also be many things. The point is rather that a certain explanatory demand arises on the relativization strategy at the level of conceptualizations and this explanatory demand is not substantially different from the explanatory demand to which the relativization was supposed to offer an answer. The original question of how something can be both one thing and many things isn't substantially different from the question of how something can be conceptualized as delivering the cardinality of exactly 1 and also be conceptualized as delivering a cardinality greater than 1 . No real explanatory progress is made.

The question arises for any reasonable account of adequacy and exclusion applied to conceptualizations. ${ }^{11}$ Consider a simple deflationary proposal for unpacking these

\footnotetext{
11 One might think that the count-based views goes naturally with a scepticism about the idea that there is an Archimedean standpoint from which to compare our conceptualizations of the word with the world itself (see e.g. Putnam 2000: p. 181) and hence that any notion of 'adequacy' is misplaced. Even on such a view, however, we presumably want to say that the conceptualization of something as a deck of cards somehow excludes a conceptualization of it as a frog (that is to say, not anything goes). How then is there not a similar
} 
notions. One might think that the conceptualization of a portion of reality $\mathrm{r}$ as $\mathrm{F}$ delivers a cardinality of 1 if and only if $r$ is a single F. Indeed, it seems natural to take the right side to explain the left side of the bi-conditional: the conceptualization of some portion of reality under the concept deck delivers a cardinality of 1 because it is one deck and the conceptualization of some portion of reality under the concept card delivers a cardinality of 52 because it is 52 cards. The moment we explain the adequacy of a given conception in terms of how things are, we start to run in a tight explanatory circle: we can adequately conceptualize $r$ as one thing and as many things because $r$ is one thing and $r$ is many things, and $r$ can be both one thing and many things because it is only one thing relative to the conceptualization as one thing and many things relative to the conceptualization as many things. This explanatory circle is uncomfortably tight.

If we want to avoid the circularity and yet explain why certain conceptualizations are adequate along deflationary lines, one might think that explanations must stop with simple predications: we must insist that we can adequately conceptualize the portion of reality as one deck and as many cards because it is one deck and many cards (but not a frog), and there is no further explanation of the latter fact in terms of conceptualizations. It simply is one deck and many cards, but not a frog. Note however that this collapses the relativist view into the primitivist view and undermines any claim to be offering a more satisfactory account of how something can be both one thing and many things.

Perhaps an adherent of concept-based relativism can reject the demand for explanations in a different place and deny that there is any explanation to be had of why certain conceptualizations of some portion of matter are adequate and others aren't. There simply is an adequate conceptualization of the portion as a deck of cards and one as 52 cards, but not an adequate conceptualization of it as two cards or three frogs. There is no explanation to be had of why things are this way, they just are. Nor is there any explanation of why the adequate conceptualization of the portion of reality as one deck does not exclude a conceptualization of it as 52 cards yet does exclude an adequate conceptualization of it as two cards. It should be clear that this is just primitivism at the level of conceptualizations. Where one form of primitivism submits that something can be both one and many things, relativism of this kind just submits that there can be adequate conceptualizations of it both as one thing and as many things.

Concept-based relativism has no explanatory advantage over the primitivist view, at least not when it comes to the central question of how the same portion of reality can be both one thing and many things.

\section{Relativization to counts}

One might think that the above issues arise from appealing to conceptualizations in particular and that a relativist view can avoid these issues by appealing to parameters

Footnote 11 continued

exclusion between conceptualization as one thing and as many things? The objection of explanatory vacuity does not strictly speaking assume that the adequacy of conceptualizations must be explained in terms of how the world is. The objection only requires an incompatibility of different conceptualizations. 
of a different sort. In Baxter (1988), one of the earliest defences of composition as identity, we find an appeal to parameters that Baxter calls 'counts':

I make sense of many-one identity by positing that identity (in the familiar sense), number, and existence are relative to what I call 'counts'. There is no one count of what exists, there are many. (Baxter 1988: p. 193).

I will be using 'count' as a technical term for the results of a given way of counting. [...] The results of a way of counting - a count - would be specified by saying what things are counted as one thing. So, for instance, one could specify a count by saying, 'the desk counts as one thing, the chair counts as one thing, each of these pencils counts as one thing,' etc. (Baxter 1988: pp. 200-201).

More recently, Baxter is explicit that this isn't meant to be a version of the conceptualization strategy, because the counts don't depend on how we conceive things to be:

How many things something is depends on what is identical and distinct from what, and that is independent of ways of conceiving things. What is identical and distinct from what is a matter of how things are in themselves. (Baxter 2014: p. 252).

We should count (where 'count' now refers to an activity on our part) a portion as one when that portion is one relative to one count (where 'count' now refers to a mindindependent parameter) and as many when it's many relative to a different count. Its being one or many is independent of our conceiving it as such. Call this count-based relativism. $^{12}$

On Baxter's understanding of counts they are not merely the standards or conventions that regulate the human practice of counting in a certain way. But if not that, then what are counts? Baxter suggests that a count is the 'result of a way of counting' (1988: p. 200). But it's unclear what it is to be a result of a way of counting, in particular, because counts are in no way meant to be mind-dependent. Baxter also states that we 'specify' a count by specifying which things are counted as one thing relative to the count. Thus, the suggestion might be that a specification of which things are counted as one thing relative to the count is a specification of the nature of the given count, giving a canonical real definition of the parameter.

If we take the specification of a count as a guide to the nature of counts in this way, one might think that the count consists in the states of affairs concerning which things are identical and which are distinct. On this line of thinking, we might have:

count $\mathrm{C}=$ the states of affairs of there being something that is identical to the ace of spades and distinct from the king of spades and from ... and there being

\footnotetext{
12 Count-based relativism is not simply a label for Baxter's view. Baxter's view is more involved, in particular relying on so-called aspects which we specify using qualifier phrases (see Baxter 1988) and a modification of Leibniz's Law (Baxter 1988: p. 205). Count-based relativism only concerns a relativization to counts, where counts are not understood as conceptualizations or representational parameters in any way. If the vacuity worry is correct, then if Baxter's account after all explains how there can be many-one identity, it's not the relativization to counts that does the explanatory work. Count-based relativism is also discussed in Spencer (2017: §4).
} 
something that is identical to the king of spades and distinct from the ace of space and from ...

count $\mathrm{D}=$ the states of affairs of there being something that is identical to the deck of cards and distinct from ...

Since we aim to uphold composition as identity, we take the cards mentioned in the specification of count $\mathrm{C}$ to be the same portion of reality as the deck of cards mentioned in the specification of count D. But the identity of the deck with the cards, one might wonder how there could be these states of affairs in the first place. That is, imagine someone were to offer the following story:

The portion of reality $r$ can be both one thing and many things. How can one make sense of the same portion of reality being one thing as well as many things? Well it's one relative to parameter $i$ and many relative to parameter $j$. What is $i$ ? It's the states of affairs of $r$ 's being one thing. What is $j$ ? It's the state of affairs of $r$ 's being many things.

The explanatory circle is uncomfortably tight again. How can $i$ and $j$ both obtain (or exist) if they consist respectively in $r$ 's being one thing and r's being many things? This question is not substantially different from the original question of how $r$ can be both one and many. The state of affairs of $r$ 's being F obtains if and only if $r$ is F. To assume that the two states of affairs can both obtain is to assume that the same portion of reality can be both one thing and many things. But if we need to assume that the same portion of reality can be both one thing and many things in order to make sense of the existence of the relevant counts, then any further relativization to these counts seems explanatorily idle. Someone who doesn't understand how the same portion of reality can be both one thing and many things will, ipso facto, be unable to understand how there can be multiple counts in this sense. The existence of the two incompatible states of affairs is the very thing that we need to explain when we purport to explain how something can be one and many. Yet again, we are pushing a bump around under the carpet.

Baxter never explicitly states that counts are to be identified with the states of affairs of various things being one thing. Is there then perhaps a different way of understanding the counts in Baxter's framework? Jason Turner (2014) offers a helpful formal framework for Baxter's view. We can formalize counts in the way we formalize the idea that there are multiple 'ways of being' (see McDaniel 2009, 2017; Turner 2010), that is, we can treat existing in different counts as different 'ways of existing'. We introduce multiple plural quantifiers $\exists_{c} x x \ldots$ and $\exists_{d} x x \ldots$ each relativized or indexed to different counts, here $c$ and $d$ (Turner 2014: $\$ 2.1$ ). These counts aren't entities within the theory but indices in the meta-language to indicate that they correspond to different ways of existing. This way, the many-one identity of the cards and the deck consists in the sameness of that which exists in different ways, that is, in it being the case that $\exists_{c} x x \exists_{d} y y$ ( $x x=$ the deck of cards and $y y=$ the 52 cards and $\left.x x=y y\right)$.

Baxter suggests that we specify a count by specifying what objects there are 'in' the count. For example, we partly specify count $c$ by saying that $\exists_{c} x x$ ( $x x=$ the deck) and $\neg \exists_{c} x x$ ( $x x=$ the 52 cards) and we partly specify count $d$ by saying that $\exists_{d} x x$ (xx=the 
52 cards) and $\neg \exists_{d} x x$ ( $x x=$ the deck). Presumably, for there to be distinct counts is for something that exists in one way not to exist in the other way.

Besides there being distinct ways of being, we can also make sense of incompatible ways of being. Intuitively, two ways of existing are incompatible if and only if it's impossible that something exists in both ways. One might think that concrete objects and abstract objects exist in ways that are incompatible. To exist the way concrete objects exist is to exist as located in space and time, whereas to exist the way abstract objects exist is to exist as lacking a location in space or time. If so, one will think that something that exists in the concrete way cannot also exist in the abstract way, i.e. that the relevant ways of existing are incompatible.

Anyone who wonders how something can be both one and many things will likewise wonder how existing as one thing and existing as many things are not incompatible ways of existing. The counts, when understood as ways of being, are in that case incompatible ways of being. For the portion of reality to exist in the first count is for it to exist as a single thing (a deck), whereas, for this portion of reality to exist in the second count is for it to exist as multiple things ( 52 cards). So now the question arises again, how can the same portion of reality exist-as-one-thing (i.e. in one count) and exist-as-many-things (i.e. in the other count)? Formulated differently, how can there be identity between the single thing that exists in one way (namely as one thing) and the many things that exist in the different way (namely as many things). This is yet again the explanatory challenge that the relativization to counts was meant to answer.

Count-based relativism has no explanatory advantage over the primitivist view in explaining how something can be both one thing and many things. In particular, the added machinery, of the ontology of counts or the application of ontological pluralism to manifestations of cardinality, does no theoretical work in explaining how something can be both one thing and many things.

\section{Concluding remarks}

Relativization to counts cannot claim to be 'explaining' or 'making sense of' manyone identity. It doesn't help when counts are understood as the things counted and it doesn't help when counts are understood as the conceptualizations of the things counted.

One may have noticed certain parallels in the ways that the concept-based and count-based forms of relativism raised the very sort of question that they were meant to answer. Is there a general reason why the discussed relativizations do not help? The vacuity seems to lie with the nature of the parameters invoked in the relativization. There is a natural tendency to understand the parameters somehow in terms of that which is relativized to them. When we do so, the incompatibility of the relativized matters rears its head in the form of the incompatibility of the parameters. To the extent that being one thing and being many things are incompatible, the adequate conceptualization of it as one thing and the adequate conceptualization of it as many things are incompatible. Similar for the state of affairs of it being one thing and the state of affairs of it being multiple things or its existing in the two incompatible ways: these are incompatible if being one thing and being many things are incompatible. 
This diagnosis suggests a straightforward remedy: the relativist should not understand the parameters in terms of that which is relativized to the parameters. But then what are these parameters relative to which the same portion of reality can be one thing and many things? As I pointed out earlier, any puzzle can be solved through the postulation of some parameters and 'relativizing' claims that jointly engender contradiction. This sort of strategy is schematic and not automatically satisfactory. It seems objectionably ad hoc without some adequate account of the nature of the invoked parameters.

The other route for the relativist is to disown any putative explanation of how something can be one thing and many things. The view is just that something can be both one thing and many things. There is no claim to be superior to the primitivist view in offering an explanation of how this can be so. In this case, any remaining appeal to relativization and the postulation of the parameters needs to be motivated on different grounds. For example, one might hope that the relativization can do some theoretical work in providing an alternative analysis of cardinality ascriptions and hence improve on the primitivist approach to them (for a critical discussion of such accounts however, see Carrara and Lando 2017). Without any independent motivation, the relativizations are theoretical danglers.

Until these challenges are met, I see no reason why a proponent of composition as identity should prefer the relativist view to the simpler primitivist view. Relativist machinery seems gratuitous machinery. ${ }^{13}$

Open Access This article is distributed under the terms of the Creative Commons Attribution 4.0 International License (http://creativecommons.org/licenses/by/4.0/), which permits unrestricted use, distribution, and reproduction in any medium, provided you give appropriate credit to the original author(s) and the source, provide a link to the Creative Commons license, and indicate if changes were made.

\section{References}

Baxter, D. L. M. (1988). Many-one identity. Philosophical Papers, 17, 193-216.

Baxter, D. L. M. (2014). Identity, discernibility, and composition. In A. J. Cotnoir \& D. L. M. Baxter (Eds.), Composition as identity (pp. 244-253). Oxford: Oxford University Press.

Bohn, E. D. (2014). Unrestricted composition as identity. In A. J. Cotnoir \& D. L. M. Baxter (Eds.), Composition as identity (pp. 143-165). Oxford: Oxford University Press.

Cameron, R. P. (2012). Composition as identity doesn't settle the special composition question. Philosophy and Phenomenological Research, 84(3), 531-554.

Carrara, M., \& Lando, G. (2017). Composition and relative counting. Dialectica, 71(4), 489-529.

Cotnoir, A. J. (2013). Composition as general identity. In D. Zimmerman \& K. Bennett (Eds.), Oxford studies in metaphysics (Vol. 8, pp. 295-322). Oxford: Oxford University Press.

Dorr, C. (2005). On what we disagree about when we disagree about ontology. In M. E. Kalderon (Ed.), Fictionalism in metaphysics (pp. 234-286). Oxford: Oxford University Press.

Fine, K. (2001). The question of realism. Philosophers' Imprint, 1, 1-30.

Frege, G. (1884, transl. 1980). In J.L. Austin (Ed.), The foundations of arithmetic: A logico-mathematical enquiry into the concept of number (2nd ed.). Northwestern University Press.

Koslicki, K. (1997). Isolation and non-arbitrary division: Frege's two criteria for counting. Synthese, 112(3), 403-430.

Lewis, D. (1983). New work for a theory of universals. Australasian Journal of Philosophy, 61(4), 343-377. Lewis, D. (1991). Parts of classes. Oxford: Wiley.

\footnotetext{
13 Many thanks to Aaron Cotnoir and two anonymous referees for their helpful feedback.
} 
McDaniel, K. (2008). Against composition as identity. Analysis, 68(2), 128-133.

McDaniel, K. (2009). Ways of being. In D. J. Chalmers, D. Manley, \& R. Wasserman (Eds.), Metametaphysics: New essays on the foundations of ontology (pp. 290-319). Oxford: Oxford University Press.

McDaniel, K. (2017). The fragmentation of being. Oxford: Oxford University Press.

Putnam, H. (2000). The threefold cord: Mind, body, and world. Cambridge, MA: Harvard University Press.

Salmon, N. (1997). Parts, wholes, and numbers. Philosophical Perspectives, 11, 1-15.

Sider, T. (2007). Parthood. Philosophical Review, 116(2007), 51-91.

Sider, T. (2011). Writing the book of the world. New York: Oxford University Press.

Sider, T. (2014). Consequences of collapse. In A. J. Cotnoir \& D. L. M. Baxter (Eds.), Composition as identity (pp. 211-221). Oxford: Oxford University Press.

Spencer, J. (2017). Counting on strong composition as identity to settle the special composition question. Erkenntnis, 82(4), 857-872.

Turner, J. (2010). Ontological pluralism. Journal of Philosophy, 107(1), 5-34.

Turner, J. (2014). Donald Baxter's composition as identity. In A. J. Cotnoir \& D. L. M. Baxter (Eds.), Composition as identity. Oxford: Oxford University Press.

van Inwagen, P. (1994). Composition as identity. In J. Tomberlin (Ed.), Philosophical perspectives (Vol. 8, pp. 207-220). Atascadero, CA: Ridgeview.

Wallace, M. (2011). Composition as identity: Part 2. Philosophy Compass, 6(11), 817-827.

Yi, B. (1999). Is mereology ontologically innocent? Philosophical Studies, 93, 141-160.

Yi, B. (2014). Is there a plural object? In D. Baxter \& A. Cotnoir (Eds.), Composition as identity (pp. 169-191). Oxford: Oxford University Press. 